Neurosurg Focus 33 (5):E15, 2012

\title{
Patterns in neurosurgical adverse events: open cerebrovascular neurosurgery
}

\author{
Judith M. Wong, M.D., M.P.H., ${ }^{1-3}$ John E. Ziewacz, M.D., M.P.H., ${ }^{4}$ Allen L. Ho, B.A., 5 \\ Jaykar R. Panchmatia, M.P.H., M.B.B.Chir., M.R.C.S., ${ }^{6}$ Albert H. KIM, M.D., Ph.D., ${ }^{7}$ \\ Angela M. BADER, M.D., M.P.H., ${ }^{1,2,8}$ B. GregORY ThOMPSON, M.D. ${ }^{4}$ \\ Rose Du, M.D., Ph.D., ${ }^{3}$ and Atul A. Gawande, M.D., M.P.H. ${ }^{1,2,9}$ \\ ${ }^{1}$ Department of Health Policy and Management, Harvard School of Public Health; ${ }^{2}$ Center for Surgery and \\ Public Health and Departments of ${ }^{3}$ Neurosurgery, ${ }^{8}$ Anesthesiology, Perioperative and Pain Medicine, and \\ ${ }^{9}$ Surgery, Brigham and Women's Hospital; and ${ }^{5}$ Harvard Medical School, Boston, Massachusetts; \\ ${ }^{4}$ Department of Neurosurgery, University of Michigan Health Systems, Ann Arbor, Michigan; ${ }^{6}$ Department of \\ Orthopaedics and Trauma, Heatherwood and Wexham Park Hospitals, London, United Kingdom; and \\ ${ }^{7}$ Department of Neurosurgery, Barnes-Jewish Hospital, Saint Louis, Missouri
}

Object. As part of a project to devise evidence-based safety interventions for specialty surgery, we sought to review current evidence concerning the frequency of adverse events in open cerebrovascular neurosurgery and the state of knowledge regarding methods for their reduction. This review represents part of a series of papers written to consolidate information about these events and preventive measures as part of an ongoing effort to ascertain the utility of devising system-wide policies and safety tools to improve neurosurgical practice.

Methods. The authors performed a PubMed search using search terms "cerebral aneurysm", "cerebral arteriovenous malformation", "intracerebral hemorrhage", "intracranial hemorrhage", "subarachnoid hemorrhage", and "complications" or "adverse events." Only papers that specifically discussed the relevant complication rates were included. Papers were chosen to be included to maximize the range of rates of occurrence for the reported adverse events.

Results. The review revealed hemorrhage-related hyperglycemia (incidence rates ranging from $27 \%$ to $71 \%$ ) and cerebral salt-wasting syndromes $(34 \%-57 \%)$ to be the most common perioperative adverse events related to subarachnoid hemorrhage (SAH). Next in terms of frequency was new cerebral infarction associated with SAH, with a rate estimated at $40 \%$. Many techniques are advocated for use during surgery to minimize risk of this development, including intraoperative neurophysiological monitoring, but are not universally used due to surgeon preference and variable availability of appropriate staffing and equipment. The comparative effectiveness of using or omitting monitoring technologies has not been evaluated.

The incidence of perioperative seizure related to vascular neurosurgery is unknown, but reported seizure rates from observational studies range from $4 \%$ to $42 \%$. There are no standard guidelines for the use of seizure prophylaxis in these patients, and there remains a need for prospective studies to support such guidelines.

Intraoperative rupture occurs at a rate of $7 \%$ to $35 \%$ and depends on aneurysm location and morphology, history of rupture, surgical technique, and surgeon experience. Preventive strategies include temporary vascular clipping.

Technical adverse events directly involving application of the aneurysm clip include incomplete aneurysm obliteration and parent vessel occlusion. The rates of these events range from 5\% to $18 \%$ for incomplete obliteration and $3 \%$ to $12 \%$ for major vessel occlusion. Intraoperative angiography is widely used to confirm clip placement; adjuncts include indocyanine green video angiography and microvascular Doppler ultrasonography. Use of these technologies varies by institution.

Discussion. A significant proportion of these complications may be avoidable through development and testing of standardized protocols to incorporate monitoring technologies and specific technical practices, teamwork and communication, and concentrated volume and specialization. Collaborative monitoring and evaluation of such protocols are likely necessary for the advancement of open cerebrovascular neurosurgical quality.

(http://thejns.org/doi/abs/10.3171/2012.7.FOCUS12181)

KEY WoRds • surgical safety • adverse events • perioperative care

$\mathrm{P}$ ROGRESS in the science of improving surgical safety has been notable in recent years. Methods for evaluating outcomes have been developed and de-

\footnotetext{
Abbreviations used in this paper: $\mathrm{ICG}=$ indocyanine green; $\mathrm{MEP}$ $=$ motor evoked potential; SAH = subarachnoid hemorrhage; SSEP

= somatosensory evoked potential.
}

ployed, $15,27,28,41,70,76,114$ and the resulting data have been used to investigate patterns of errors and complications. From these findings, solutions have been designed and tested with sometimes striking improvements, whether based on simple process tools like checklists ${ }^{15,16,34,113}$ or technological changes. ${ }^{29,86,110}$ Neurosurgery is a high-risk surgical specialty and is beginning to pursue systematic, 
nationwide approaches to measuring and improving outcomes and developing evidence-based guidelines for a variety of neurosurgical disorders. As part of a project funded by the US Agency for Healthcare Research and Quality to devise evidence-based checklists and protocols for specialty surgery, we sought to review current evidence in neurosurgery concerning the frequency of adverse events in practice, their patterns, and the state of knowledge about how to improve them. We hypothesized that this consolidation of existing data, even if commonly known to neurosurgeons, will not only highlight the need for system-wide policies and safety tools to improve neurosurgical practice but will inform future efforts to develop and implement these tools and policies. This document reviews such evidence for open cerebrovascular neurosurgery.

Much of the data describe adverse events related to surgery and perioperative care for patients with ruptured aneurysms and $\mathrm{SAH}$, as these patients are the most severely ill. However, many of the same precautions are taken for elective procedures for the treatment of these and other vascular entities even though these procedures are performed under substantially more controlled conditions.

\section{Scope of the Problem}

Approximately $2 \%$ of the general population has intracranial aneurysms, based on autopsy and angiographic studies. ${ }^{15}$ Many of these aneurysms have a low risk of hemorrhage: ${ }^{115}$ however, approximately 30,000 people suffer catastrophic aneurysmal SAH in the US each year, with an incidence of 2-23 per 100,000 person-years..$^{9,38,53}$ The indications for treatment of unruptured aneurysms remain controversial but depend on aneurysm size, location, and morphology; age of the patient; family and personal history of aneurysm rupture; and experience and availability of microvascular neurosurgeons and neurointerventionalists. ${ }^{47,115}$ According to data from the National Inpatient Sample, 62,820 aneurysms were treated with open surgical clipping between 2002 and 2007 (http:// hcupnet.ahrq.gov/HCUPnet.jsp).

The perioperative morbidity and mortality rates for aneurysm surgery vary depending on a variety of patient and aneurysm characteristics. According to 2 meta-analyses, for patients with unruptured aneurysms the morbidity rate ranges from $4 \%$ to $11 \%$ and the mortality rate from $1 \%$ to $3 \% .{ }^{44,80}$ For patients with ruptured aneurysms, perioperative outcome is inexorably linked to hemorrhage severity, making assessment of such complication rates difficult. ${ }^{9}$ Regardless, the most common adverse events that occur following, but not necessarily as the result of, open cerebrovascular surgery are hemorrhage-related hyperglycemia, cerebral salt-wasting syndrome, new cerebral infarction, perioperative seizure, intraoperative rupture, incomplete aneurysm obliteration, major vessel occlusion, failure to secure the rupture site, and other medical adverse events (Table 1). Many of these events are related to the severity of intracranial hemorrhage and are not a direct result of surgery. Some, such as incomplete aneurysm obliteration, may represent an intentional strategy to prevent adverse consequences such as cerebral infarction. We nonetheless present them here to remain as comprehensive as possible when designing targeted safety tools.

\section{Methods}

We performed a PubMed search of the English literature using the search terms "cerebral aneurysm," "cerebral arteriovenous malformation," "intracerebral hemorrhage," "intracranial hemorrhage," "subarachnoid hemorrhage," AND "complications" or "adverse events." This series of papers reflects our efforts to encompass all of neurosurgery broadly; thus we describe here the most commonly occurring events in cerebrovascular surgery. We have chosen the surgical treatment of SAH and aneurysms, the conditions most commonly treated by vascular neurosurgeons, to represent the field and to focus the review. Only papers that specifically discussed the relevant complication rates were included. Papers were selected to maximize the range of rates of occurrence for the reported adverse events rather than to include all possible studies. We did not impose any threshold of minimum patients or publication year; however, we attempted to choose series that were representative of the most common complications.

\section{Hemorrhage-Related Hyperglycemia}

Patients with SAH are at increased risk of perioperative hyperglycemia, with an incidence of $27 \%$ to $71 \%$., 60 Recent data link serum glucose levels to neurological outcome. Several observational studies suggest an association between elevated intraoperative and/or perioperative glucose levels and subsequent cognitive impairment and decreased gross neurological function following surgery for ruptured aneurysm(s). ${ }^{49,50,60,75}$ A small, prospective randomized pilot study found lower infection rates with aggressive compared with standard glycemic control but was not sufficiently powered to detect any difference in mortality or functional outcome. ${ }^{11}$ Another observational study found an association between inpatient hyperglycemia and increased risk for vasospasm. ${ }^{5}$ Although close monitoring of perioperative serum glucose is currently recommended in other fields, ${ }^{108}$ emerging data suggest that tight glucose control may actually be harmful to the injured brain. ${ }^{105}$ There is no prospective, randomized trial to evaluate tight glycemic control with outcomes in neurosurgery; thus no standard guidelines are currently recommended.

\section{Cerebral Salt-Wasting Syndrome}

Hyponatremia is the most frequently occurring electrolyte abnormality in clinical medicine, ${ }^{12}$ and it is particularly common among neurosurgical patients, with an estimated prevalence of $34 \%$ to $57 \%$ in patients with SAH. ${ }^{33,98}$ This patient population in particular experiences increased morbidity in the setting of hyponatremia. ${ }^{84}$ Data from one retrospective study of patients with SAH suggest an association between hyponatremia and increased risk for cerebral infarction compared with normonatremic patients. ${ }^{33} \mathrm{~A}$ more recent observational study 
Adverse events in open cerebrovascular neurosurgery

TABLE 1: Frequency of adverse events reported in cerebrovascular surgery*

\begin{tabular}{|c|c|c|c|}
\hline AE w/ Authors \& Year & Sample Size (no. of cases) & Aneurysm Rupture Status & Frequency (\%) \\
\hline \multicolumn{4}{|l|}{ hemorrhage-related hyperglycemia } \\
\hline Badjatia et al., 2005 & 352 & ruptured & 71 \\
\hline McGirt et al., 2007 & 97 & ruptured & 27 \\
\hline \multicolumn{4}{|l|}{ cerebral salt-wasting syndrome } \\
\hline Sherlock et al., 2006 & 316 & ruptured & 57 \\
\hline Hasan et al., 1990 & 208 & ruptured & 34 \\
\hline \multicolumn{4}{|l|}{ new cerebral infarction } \\
\hline Rabinstein et al., 2004 & 143 & ruptured & 40 \\
\hline Umredkar et al., 2010 & 174 & ruptured & 39 \\
\hline \multicolumn{4}{|l|}{ perioperative seizure } \\
\hline Shaw \& Foy, 1991 & 252 & ruptured & 42 \\
\hline Rhoney et al., 2000 & 95 & ruptured & 4 \\
\hline \multicolumn{4}{|l|}{ intraoperative rupture } \\
\hline Sandalcioglu et al., 2004 & 169 & ruptured & 35 \\
\hline Schramm \& Cedzich, 1993 & 222 & ruptured & 27 \\
\hline Batjer \& Samson, 1986 & 307 & mixed & 19 \\
\hline Elijovich et al., 2008 & 711 & ruptured & 19 \\
\hline Fridriksson et al., 2002 & 355 & mixed & 18 \\
\hline Leipzig et al., 2005 & 1694 & mixed & 7 \\
\hline \multicolumn{4}{|l|}{ incomplete aneurysm obliteration† } \\
\hline Molyneux et al., 2002 & 1012 & ruptured & 18 \\
\hline Kivisaari et al., 2004 & 808 & mixed & 12 \\
\hline Johnston et al., 2008 & 706 & ruptured & 8 \\
\hline Macdonald et al., 1993 & 78 & mixed & 8 \\
\hline McLaughlin \& Bojanowski, 2004 & 143 & ruptured & 5 \\
\hline \multicolumn{4}{|l|}{ major vessel occlusion } \\
\hline Macdonald et al., 1993 & 78 & mixed & 12 \\
\hline Kivisaari et al., 2004 & 808 & mixed & 5 \\
\hline Fridriksson et al., 2002 & 355 & mixed & 3 \\
\hline \multicolumn{4}{|l|}{ failure to secure rupture site } \\
\hline Molyneux et al., 2002 & 1012 & ruptured & 6 \\
\hline Macdonald et al., 1993 & 78 & mixed & 4 \\
\hline Kivisaari et al., 2004 & 808 & mixed & 3 \\
\hline McLaughlin \& Bojanowski, 2004 & 143 & ruptured & 1 \\
\hline \multicolumn{4}{|l|}{ other medical adverse events } \\
\hline Fridriksson et al., 2002 & 355 & mixed & 17 \\
\hline Molyneux et al., 2002 & 1012 & ruptured & 2 \\
\hline
\end{tabular}

failed to corroborate these data, however. ${ }^{78}$ Aggressive intravenous fluid and/or mineralocorticoid repletion reduces the incidence of hyponatremia and hypovolemia, ${ }^{65,100}$ but no controlled trials exist to correlate this correction with decreased risk for cerebral ischemia.

\section{New Cerebral Infarction}

Cerebral infarction associated with $\mathrm{SAH}$ is welldocumented, with a reported incidence of approximately $40 \% .{ }^{81,107}$ This rate is no better than reports from 25 years ago in the original Cooperative Aneurysm Study. ${ }^{1}$ Occur- rence of early infarct varies with clinical and radiographical grade and nuances of surgical technique, whereas late infarct is related mostly to vasospasm. ${ }^{107}$ Patients with cerebral infarction after SAH are much less likely to make a good recovery than those without. ${ }^{81,82,107}$

There are many causes of new infarction after $\mathrm{SAH}$. Many result directly from the initial hemorrhage or subsequent ICP elevation. ${ }^{17,94,99}$ These are largely unavoidable. Many late infarcts result from vasospasm. Prevention of these spasm-related infarcts includes intensive critical-care management with goal-directed hyperten- 


\section{J. M. Wong et al.}

sion, hypervolemia, and hemodilution as described in the literature. ${ }^{42,67,90,109}$ Vasospasm treatment and stroke prevention also include angiographic intervention at many institutions. ${ }^{10,43,83}$

The proportion of new infarcts that can be attributed directly to surgery is unknown, but it is likely a small fraction. Many techniques are employed during surgery to minimize the risk of this development. Intraoperative neurophysiological monitoring for cerebral aneurysm surgery classically consists of some combination of MEPs and SSEPs ${ }^{30}$ Other intraoperative measures such as Doppler ultrasonography, electroencephalography when possible, and electrocorticography have also been employed with some benefit. ${ }^{18,71}$ Such monitoring is primarily used to detect early and potentially reversible ischemic or mechanical damage, with the intent of altering surgical strategy to minimize iatrogenic neurological deficit. . $^{2,36,63}$ Monitoring of SSEPs is particularly useful during temporary vessel occlusion (discussed in a subsequent section), as alterations in SSEP are reversible and associated with good neurological outcome when promptly corrected. ${ }^{96}$ Randomized trials of this technique do not exist and may not be warranted given the plethora of supporting data. The existing studies have led monitoring to be widely recommended as a technique to prevent postoperative infarction. However, it is not universally used due to variable availability of appropriate staffing and equipment as well as to surgeon preference.

\section{Perioperative Seizure}

The incidence of perioperative seizure related to vascular neurosurgery is unknown, but reported values from observational studies range from $4 \%$ to $42 \%$ in patients undergoing craniotomy for aneurysm. ${ }^{56,87,97}$ This incidence is thought to be declining with the maturation of microsurgical techniques. ${ }^{7}$ The use of perioperative seizure prophylaxis is common but variable. To date, no randomized trials have evaluated use or duration of seizure prophylaxis following craniotomy for aneurysm. Existing data suggest reduction in immediate postoperative seizure rate but are conflicting regarding longer-term seizure reduction and functional outcome. ${ }^{89}$ The reason for this observation remains unclear but is supported in other studies of prophylactic seizure therapy for nonaneurysmal intracranial hemorrhage. ${ }^{62,68,89}$ There are no standard guidelines for the use of seizure prophylaxis in this patient population, and there remains a need for strong prospective and randomized studies to support such guidelines.

\section{Intraoperative Rupture}

Intraoperative rupture (IOR) is an unexpected and potentially catastrophic complication of aneurysm surgery. ${ }^{13}$ Its incidence ranges from $7 \%$ to $35 \%$ in observational series and depends on aneurysm location and morphology, history of rupture, surgical technique, and surgeon experience. $8,21,26,52,93,95$ Whether its occurrence portends worse prognosis remains unclear. Some limited retrospective data suggest no association between IOR and outcome, ${ }^{93}$ while other data suggest a negative effect. One retrospective study of 307 consecutive aneurysm procedures found a significant association between IOR and poor outcome. ${ }^{8}$ The multiinstitutional CARAT study demonstrated a $19 \%$ risk of IOR, with periprocedural death or disability in the IOR group almost double that of the group without IOR. ${ }^{21}$ Other authors suggest that rapid IOR control, reflecting the team's level of preparation, is more important than its incidence in determining outcome..$^{95}$

The use of temporary vascular clipping may help to prevent intraoperative rupture by facilitating dissection around the aneurysm and parent vessel reconstruction. ${ }^{104}$ It remains unknown how long a major vessel may be safely occluded before irreversible ischemia results. Data from retrospective studies suggest a maximum of 20 minutes for temporary clipping depending on the artery involved, with patients over 60 years of age or those with more severe Hunt and Hess grades even more susceptible to ischemic changes. ${ }^{72,92}$ In a prospective, uncontrolled study of a series of 126 cases in which temporary clipping was performed, occlusion time greater than 20 minutes was corroborated as an independent predictor of postoperative infarct, even with induced hypothermia and hypertension, and intravenous mannitol administration during temporary clipping. ${ }^{73}$ Some authors advocate brief occlusion times followed by reperfusion; ${ }^{9}$ however, this practice is debated given that multiple occlusion-reperfusion cycles may actually worsen ischemic injury. ${ }^{104}$

Induced hypothermia and barbiturate neuroprotection may prevent or mitigate ischemic events during aneurysm surgery, particularly during temporary clipping. ${ }^{59}$ While animal studies suggest both long- and short-term benefit, ${ }^{88,111,112,118}$ prospective randomized trials in humans have failed to show convincing data..$^{35,106}$

No prospective, randomized studies exist to compare surgery with temporary occlusion, without temporary occlusion, and with multiple shorter episodes of occlusion followed by intermittent reperfusion. Use of temporary clipping varies by aneurysm morphology, vascular anatomy, and surgeon preference and is not recommended in formal guidelines, but it is considered by most to be an important adjunct to open cerebrovascular neurosurgery.

Similar to intraoperative monitoring, the use of temporary clipping is not conducive to guidelines or the design of safety tools. However, targeted safety interventions should include preparation for such interventions long before the start of the procedure. Practices such as intraoperative monitoring and temporary clipping require timely and coordinated efforts from all members of the surgical team, including the surgeon, anesthesiologist, and nursing staff. Preparation therefore requires extensive planning, which should occur before the procedure rather than during an emergent situation such as early rupture before proximal control has been obtained.

\section{Incomplete Aneurysm Obliteration, Major Vessel Occlusion}

Technical adverse events directly involving application of the aneurysm clip include incomplete aneurysm obliteration and parent vessel occlusion. While many of these events are intentional and unavoidable due to the vascular anatomy, some are unintentional and/or unexpected. These occurrences depend largely on aneurysm morphology, surrounding vessel anatomy, rupture sta- 
tus, and surgical experience, and the rates range from $5 \%$ to $18 \%$ for incomplete obliteration and from $3 \%$ to $12 \%$ for major vessel occlusion, according to observational studies using postoperative angiography. ${ }^{39,45,54,61,64}$ The incomplete obliteration incidence of $18 \%$ reported in ISAT is likely an overestimate, given that only half of the surgically treated patients underwent postoperative angiography and the majority of these angiographic studies were performed between 2-12 months after surgery. ${ }^{64}$ Similarly, in the study by McLaughlin and Bojanowski, ${ }^{61}$ postoperative imaging was not performed in all cases. Fridriksson et al. ${ }^{26}$ report the lowest rate of vessel occlusion, but their analysis was performed in the setting of intraoperative complications, and the mode of detection was not specified.

Intraoperative angiography is widely used to confirm parent vessel and branch patency as well as aneurysm obliteration during the procedure, and the results often alter the surgical course. . $^{3,46,58,69,77}$ Intraoperative angiography is particularly useful in the setting of complex anatomy and/or giant aneurysm. ${ }^{23,74}$ Adjunctive modalities include ICG video angiography and microvascular Doppler ultrasonography; $2,6,14,24,40,57,79,101$ benefit has been shown for both in small uncontrolled series but has not yet been confirmed in large randomized trials. The technology of CT angiography is improving, and this modality may also be used in the postoperative setting, particularly with aneurysms in the anterior circulation, though conventional angiography remains the gold standard. ${ }^{19,55,119}$

Avoidance of aneurysm clip misplacement, which results in incomplete aneurysm obliteration and/or parent vessel occlusion, has improved with the development of microsurgical technique, optimization of patient positioning, and formalized fellowship training. There is some evidence supporting the value of specialization and increased surgical case volume for reducing complications in carotid endarterectomy, ${ }^{31,32}$ and this is likely to hold true for other open cerebrovascular procedures as well.

Since Kurze's initial use in the 1950s, the operating microscope has revolutionized neurosurgery and has become the standard of care for open cerebrovascular procedures..$^{20,48}$ Microscope-related errors include use of the improper microscope, improper microscope balance, and delays due to the absence or delayed delivery of related equipment (such as drape) (B.G. Thompson, personal communication, 2010). Such errors can result in technical failure, increased infection risk due to prolonged procedure time, or inability to complete the procedure.

Patient positioning is critical for the surgeon, who requires the most favorable access to the vascular lesion, ${ }^{37}$ and the anesthesiologist, who must maintain cerebral venous outflow as well as prevent compressive peripheral neuropathy..$^{91}$ These considerations are of particular importance in cerebrovascular neurosurgery because of the extended length of these procedures. ${ }^{4}$ Complications related to positioning and/or securing of the patient's head are rare but potentially catastrophic and completely avoidable. Such occurrences include structural failure of the Mayfield headrest, ${ }^{103} \mathrm{CSF}$ rhinorrhea, ${ }^{66}$ or epidural hematoma from laceration of the middle meningeal artery by the pins. ${ }^{51}$

\section{Failure to Secure Rupture Site}

Unlike incomplete aneurysm obliteration in general, failure to secure the rupture site of a ruptured aneurysm can lead to early rerupture and subsequent mortality; it therefore must be promptly remedied. Incidence of early rerupture in the 1st year after treatment is approximately $2 \%$ according to the CARAT investigators, with half of reruptures occurring within 3 days after treatment. ${ }^{39}$ Failure to secure the rupture site is rarely reported in the literature; however, it may be inferred from the rate of retreatment immediately following surgical clipping. The $6 \%$ "incomplete occlusion" rate reported in the ISAT study represents a select subgroup since less than half of patients underwent postoperative angiography, and the majority of the angiograms were performed between 2 and 12 months postoperatively. ${ }^{64}$ The CARAT study made no mention of a retreatment rate, although the investigators noted that the rerupture rate in aneurysms that were less than $70 \%$ occluded was similar to that of untreated ruptured aneurysms in prior studies. ${ }^{39}$ Kivisaari et al ${ }^{45}$ noted neck remnants in $9 \%$ of aneurysms in their series and fundus remnants in 3\%, but only mentioned retreatment in the case of major vessel occlusion. Macdonald and colleagues $^{54}$ reported a $4 \%$ incidence of completely unclipped aneurysms discovered on postoperative angiography; all were successfully obliterated on repeat surgery. Of the incompletely obliterated aneurysms found in the study by McLaughlin and Bojanowski, ${ }^{61}$ two were intentionally left incompletely obliterated at surgery and were subsequently obliterated endovascularly. The incidence of this adverse event has declined with more widespread use of intraoperative angiography (with or without ICG). Preventive techniques include those for avoidance of a misplaced aneurysm clip discussed in the previous section.

\section{Other Medical Adverse Events}

Other medical adverse events such as myocardial infarction, thromboembolism, septicemia, meningitis, or respiratory disease may also complicate open cerebrovascular procedures in the perioperative period. Given the severity of the disease, there are few reports of these rates directly related to surgery. For two of the studies on our review, other medical adverse events were reported to occur in $2 \%-17 \%$ of cases. ${ }^{26,64}$ This wide range is likely due to incomplete reporting and different definitions of perioperative complications.

It is unknown what proportion of these events could have been prevented. Good quality perioperative care including preoperative medical optimization, ${ }^{25}$ infection control, ${ }^{102,117}$ and judicious use of mechanical and pharmacological thromboprophylaxis ${ }^{85}$ may be of benefit. Adherence to these practices is likely inconsistent.

\section{Conclusions}

Open cerebrovascular neurosurgery is a high-risk procedural specialty. A significant proportion of these complications may be avoidable using practices to encourage standardized protocols, improved teamwork and communication, increased use of beneficial technologies, 
and concentrated experiences and specializations. These ideas, including centralization of care, are discussed in more detail in the summary paper of this series ${ }^{116}$ Concerted efforts aimed at large-scale monitoring of neurosurgical complications and consistent quality improvement within these highlighted realms may significantly improve patient outcomes.

\section{Disclosure}

This work is funded by a US Agency for Healthcare Quality and Research grant (1R18 HS018537-01). Dr. Gawande receives royalties on his publications and books about patient safety.

Author contributions to the study and manuscript preparation include the following. Conception and design: Gawande, Bader Acquisition of data: Wong, Ziewacz, Ho. Analysis and interpretation of data: Gawande, Wong. Drafting the article: Wong, Ziewacz, Ho, Panchmatia. Critically revising the article: all authors. Reviewed submitted version of manuscript: Gawande, Wong, Bader. Approved the final version of the manuscript on behalf of all authors: Gawande. Study supervision: Gawande, Bader.

\section{References}

1. Adams HP Jr, Kassell NF, Torner JC, Haley EC Jr: Predicting cerebral ischemia after aneurysmal subarachnoid hemorrhage: influences of clinical condition, CT results, and antifibrinolytic therapy. A report of the Cooperative Aneurysm Study. Neurology 37:1586-1591, 1987

2. Akdemir H, Oktem IS, Tucer B, Menkü A, Başaslan K, Günaldi O: Intraoperative microvascular Doppler sonography in aneurysm surgery. Minim Invasive Neurosurg 49:312-316, 2006

3. Alexander TD, Macdonald RL, Weir B, Kowalczuk A: Intraoperative angiography in cerebral aneurysm surgery: a prospective study of 100 craniotomies. Neurosurgery 39:10-18, 1996

4. American Society of Anesthesiologists: Practice advisory for the prevention of perioperative peripheral neuropathies: a report by the American Society of Anesthesiologists Task Force on Prevention of Perioperative Peripheral Neuropathies. Anesthesiology 92:1168-1182, 2000

5. Badjatia N, Topcuoglu MA, Buonanno FS, Smith EE, Nogueira RG, Rordorf GA, et al: Relationship between hyperglycemia and symptomatic vasospasm after subarachnoid hemorrhage. Crit Care Med 33:1603-1609, 2005

6. Bailes JE, Tantuwaya LS, Fukushima T, Schurman GW, Davis D: Intraoperative microvascular Doppler sonography in aneurysm surgery. Neurosurgery 40:965-972, 1997

7. Baker CJ, Prestigiacomo CJ, Solomon RA: Short-term perioperative anticonvulsant prophylaxis for the surgical treatment of low-risk patients with intracranial aneurysms. Neurosurgery 37:863-871, 1995

8. Batjer H, Samson D: Intraoperative aneurysmal rupture: incidence, outcome, and suggestions for surgical management. Neurosurgery 18:701-707, 1986

9. Bederson JB, Connolly ES Jr, Batjer HH, Dacey RG, Dion JE, Diringer MN, et al: Guidelines for the management of aneurysmal subarachnoid hemorrhage: a statement for healthcare professionals from a special writing group of the Stroke Council, American Heart Association. Stroke 40:994-1025, 2009

10. Bejjani GK, Bank WO, Olan WJ, Sekhar LN: The efficacy and safety of angioplasty for cerebral vasospasm after subarachnoid hemorrhage. Neurosurgery 42:979-987, 1998

11. Bilotta F, Spinelli A, Giovannini F, Doronzio A, Delfini R, Rosa G: The effect of intensive insulin therapy on infection rate, vasospasm, neurologic outcome, and mortality in neurointensive care unit after intracranial aneurysm clipping in patients with acute subarachnoid hemorrhage: a randomized prospective pilot trial. J Neurosurg Anesthesiol 19:156-160, 2007

12. Boscoe A, Paramore C, Verbalis JG: Cost of illness of hyponatremia in the United States. Cost Eff Resour Alloc 4:10, 2006

13. Chandler JP, Getch CC, Batjer HH: Intraoperative aneurysm rupture and complication avoidance. Neurosurg Clin $\mathbf{N}$ Am 9:861-868, 1998

14. Dashti R, Laakso A, Niemelä M, Porras M, Celik O, Navratil $\mathrm{O}$, et al: Application of microscope integrated indocyanine green video-angiography during microneurosurgical treatment of intracranial aneurysms: a review. Acta Neurochir Suppl 107:107-109, 2010

15. de Vries EN, Hollmann MW, Smorenburg SM, Gouma DJ, Boermeester MA: Development and validation of the SURgical PAtient Safety System (SURPASS) checklist. Qual Saf Health Care 18:121-126, 2009

16. de Vries EN, Prins HA, Crolla RM, den Outer AJ, van Andel G, van Helden SH, et al: Effect of a comprehensive surgical safety system on patient outcomes. N Engl J Med 363:19281937,2010

17. Deb P, Sharma S, Hassan KM: Pathophysiologic mechanisms of acute ischemic stroke: an overview with emphasis on therapeutic significance beyond thrombolysis. Pathophysiology 17:197-218, 2010

18. Debatisse D, Pralong E, Dehdashti AR, Regli L: Simultaneous multilobar electrocorticography ( $\mathrm{mEcoG}$ ) and scalp electroencephalography (scalp EEG) during intracranial vascular surgery: a new approach in neuromonitoring. Clin Neurophysiol 116: 2734-2740, 2005

19. Dehdashti AR, Binaghi S, Uske A, Regli L: Comparison of multislice computerized tomography angiography and digital subtraction angiography in the postoperative evaluation of patients with clipped aneurysms. J Neurosurg 104:395-403, 2006

20. Donaghy RM: The history of microsurgery in neurosurgery. Clin Neurosurg 26:619-625, 1979

21. Elijovich L, Higashida RT, Lawton MT, Duckwiler G, Giannotta S, Johnston SC: Predictors and outcomes of intraprocedural rupture in patients treated for ruptured intracranial aneurysms: the CARAT study. Stroke 39:1501-1506, 2008

22. Emerson RG, Turner CA: Monitoring during supratentorial surgery. J Clin Neurophysiol 10:404-411, 1993

23. Fahlbusch R, Nimsky C, Huk W: Open surgery of giant paraclinoid aneurysms improved by intraoperative angiography and endovascular retrograde suction decompression. Acta Neurochir (Wien) 139:1026-1032, 1997

24. Firsching R, Synowitz HJ, Hanebeck J: Practicability of intraoperative microvascular Doppler sonography in aneurysm surgery. Minim Invasive Neurosurg 43:144-148, 2000

25. Fleisher LA, Beckman JA, Brown KA, Calkins H, Chaikof E, Fleischmann KE, et al: ACC/AHA 2007 guidelines on perioperative cardiovascular evaluation and care for noncardiac surgery: a report of the American College of Cardiology/ American Heart Association Task Force on Practice Guidelines (Writing Committee to Revise the 2002 Guidelines on Perioperative Cardiovascular Evaluation for Noncardiac Surgery). Circulation 116:e418-e499, 2007

26. Fridriksson S, Säveland H, Jakobsson KE, Edner G, Zygmunt $\mathrm{S}$, Brandt L, et al: Intraoperative complications in aneurysm surgery: a prospective national study. J Neurosurg 96:515522,2002

27. Gawande AA, Studdert DM, Orav EJ, Brennan TA, Zinner MJ: Risk factors for retained instruments and sponges after surgery. N Engl J Med 348:229-235, 2003

28. Gawande AA, Thomas EJ, Zinner MJ, Brennan TA: The incidence and nature of surgical adverse events in Colorado and Utah in 1992. Surgery 126:66-75, 1999

29. Greenberg CC, Diaz-Flores R, Lipsitz SR, Regenbogen SE, Mulholland L, Mearn F, et al: Bar-coding surgical sponges 
to improve safety: a randomized controlled trial. Ann Surg 247:612-616, 2008

30. Guérit JM: Neuromonitoring in the operating room: why, when, and how to monitor? Electroencephalogr Clin Neurophysiol 106:1-21, 1998

31. Hannan EL, Popp AJ, Feustel P, Halm E, Bernardini G, Waldman J, et al: Association of surgical specialty and processes of care with patient outcomes for carotid endarterectomy. Stroke 32:2890-2897, 2001

32. Hannan EL, Popp AJ, Tranmer B, Fuestel P, Waldman J, Shah D: Relationship between provider volume and mortality for carotid endarterectomies in New York state. Stroke 29:22922297, 1998

33. Hasan D, Wijdicks EF, Vermeulen M: Hyponatremia is associated with cerebral ischemia in patients with aneurysmal subarachnoid hemorrhage. Ann Neurol 27:106-108, 1990

34. Haynes AB, Weiser TG, Berry WR, Lipsitz SR, Breizat AH, Dellinger EP, et al: A surgical safety checklist to reduce morbidity and mortality in a global population. N Engl J Med 360:491-499, 2009

35. Hindman BJ, Bayman EO, Pfisterer WK, Torner JC, Todd MM: No association between intraoperative hypothermia or supplemental protective drug and neurologic outcomes in patients undergoing temporary clipping during cerebral aneurysm surgery: findings from the Intraoperative Hypothermia for Aneurysm Surgery Trial. Anesthesiology 112:86-101, 2010

36. Holland NR: Subcortical strokes from intracranial aneurysm surgery: implications for intraoperative neuromonitoring. J Clin Neurophysiol 15:439-446, 1998

37. Iihara K, Chopra G, Tymianski: Surgical approaches for anterior circulation aneurysms, in Winn HR, Youmans JR (eds): Youmans Neurological Surgery, ed 5. Philadelphia: WB Saunders, 2004, Vol 2, pp 1868-1894

38. Ingall T, Asplund K, Mähönen M, Bonita R: A multinational comparison of subarachnoid hemorrhage epidemiology in the WHO MONICA stroke study. Stroke 31:1054-1061, 2000

39. Johnston SC, Dowd CF, Higashida RT, Lawton MT, Duckwiler GR, Gress DR: Predictors of rehemorrhage after treatment of ruptured intracranial aneurysms: the Cerebral Aneurysm Rerupture After Treatment (CARAT) study. Stroke 39:120125,2008

40. Kapsalaki EZ, Lee GP, Robinson JS III, Grigorian AA, Fountas KN: The role of intraoperative micro-Doppler ultrasound in verifying proper clip placement in intracranial aneurysm surgery. J Clin Neurosci 15:153-157, 2008

41. Khuri SF, Daley J, Henderson W, Hur K, Demakis J, Aust JB, et al: The Department of Veterans Affairs' NSQIP: the first national, validated, outcome-based, risk-adjusted, and peercontrolled program for the measurement and enhancement of the quality of surgical care. Ann Surg 228:491-507, 1998

42. Kim DH, Haney CL, Van Ginhoven G: Reduction of pulmonary edema after SAH with a pulmonary artery catheterguided hemodynamic management protocol. Neurocrit Care 3:11-15, 2005

43. Kimball MM, Velat GJ, Hoh BL: Critical care guidelines on the endovascular management of cerebral vasospasm. Neurocrit Care 15:336-341, 2011

44. King JT Jr, Berlin JA, Flamm ES: Morbidity and mortality from elective surgery for asymptomatic, unruptured, intracranial aneurysms: a meta-analysis. J Neurosurg 81:837-842, 1994

45. Kivisaari RP, Porras M, Ohman J, Siironen J, Ishii K, Hernesniemi J: Routine cerebral angiography after surgery for saccular aneurysms: is it worth it? Neurosurgery 55:1015-1024, 2004

46. Klopfenstein JD, Spetzler RF, Kim LJ, Feiz-Erfan I, Han PP, Zabramski JM, et al: Comparison of routine and selective use of intraoperative angiography during aneurysm surgery: a prospective assessment. J Neurosurg 100:230-235, 2004

47. Komotar RJ, Mocco J, Solomon RA: Guidelines for the surgi- cal treatment of unruptured intracranial aneurysms: the first annual J. Lawrence Pool memorial research symposiumcontroversies in the management of cerebral aneurysms. Neurosurgery 62:183-194, 2008

48. Kriss TC, Kriss VM: History of the operating microscope: from magnifying glass to microneurosurgery. Neurosurgery 42:899-908, 1998

49. Kruyt ND, Biessels GJ, de Haan RJ, Vermeulen M, Rinkel GJ, Coert B, et al: Hyperglycemia and clinical outcome in aneurysmal subarachnoid hemorrhage: a meta-analysis. Stroke 40:e424-e430, 2009

50. Latorre JG, Chou SH, Nogueira RG, Singhal AB, Carter BS, Ogilvy CS, et al: Effective glycemic control with aggressive hyperglycemia management is associated with improved outcome in aneurysmal subarachnoid hemorrhage. Stroke 40: 1644-1652, 2009

51. Lee MJ, Lin EL: The use of the three-pronged Mayfield head clamp resulting in an intracranial epidural hematoma in an adult patient. Eur Spine J 19 (Suppl 2):S187-S189, 2010

52. Leipzig TJ, Morgan J, Horner TG, Payner T, Redelman K, Johnson CS: Analysis of intraoperative rupture in the surgical treatment of 1694 saccular aneurysms. Neurosurgery 56:455-468, 2005

53. Linn FH, Rinkel GJ, Algra A, van Gijn J: Incidence of subarachnoid hemorrhage: role of region, year, and rate of computed tomography: a meta-analysis. Stroke 27:625-629, 1996

54. Macdonald RL, Wallace MC, Kestle JR: Role of angiography following aneurysm surgery. J Neurosurg 79:826-832, 1993

55. Mamourian AC, Erkmen K, Pluta DJ: Nonhelical acquisition CT angiogram after aneurysmal clipping: in vitro testing shows diminished artifact. AJNR Am J Neuroradiol 29: 660-662, 2008

56. Manaka S, Ishijima B, Mayanagi Y: Postoperative seizures: epidemiology, pathology, and prophylaxis. Neurol Med Chir (Tokyo) 43:589-600, 2003

57. Marchese E, Albanese A, Denaro L, Vignati A, Fernandez E, Maira G: Intraoperative microvascular Doppler in intracranial aneurysm surgery. Surg Neurol 63:336-342, 2005

58. Martin N, Doberstein C, Bentson J, Vinuela F, Dion J, Becker D: Intraoperative angiography in cerebrovascular surgery. Clin Neurosurg 37:312-331, 1991

59. McDermott MW, Durity FA, Borozny M, Mountain MA: Temporary vessel occlusion and barbiturate protection in cerebral aneurysm surgery. Neurosurgery 25:54-62, 1989

60. McGirt MJ, Woodworth GF, Ali M, Than KD, Tamargo RJ, Clatterbuck RE: Persistent perioperative hyperglycemia as an independent predictor of poor outcome after aneurysmal subarachnoid hemorrhage. J Neurosurg 107:1080-1085, 2007

61. McLaughlin N, Bojanowski MW: Early surgery-related complications after aneurysm clip placement: an analysis of causes and patient outcomes. J Neurosurg 101:600-606, 2004

62. Messé SR, Sansing LH, Cucchiara BL, Herman ST, Lyden PD, Kasner SE: Prophylactic antiepileptic drug use is associated with poor outcome following ICH. Neurocrit Care 11:38-44, 2009

63. Mizoi K, Yoshimoto T: Permissible temporary occlusion time in aneurysm surgery as evaluated by evoked potential monitoring. Neurosurgery 33:434-440, 1993

64. Molyneux A, Kerr R, Stratton I, Sandercock P, Clarke M, Shrimpton J, et al: International Subarachnoid Aneurysm Trial (ISAT) of neurosurgical clipping versus endovascular coiling in 2143 patients with ruptured intracranial aneurysms: a randomised trial. Lancet 360:1267-1274, 2002

65. Mori T, Katayama Y, Kawamata T, Hirayama T: Improved efficiency of hypervolemic therapy with inhibition of natriuresis by fludrocortisone in patients with aneurysmal subarachnoid hemorrhage. J Neurosurg 91:947-952, 1999

66. Moumoulidis I, Fernandes H: CSF rhinorrhea secondary to use of a Mayfield head clamp. Ear Nose Throat J 87:E1-E3, 2008 


\section{J. M. Wong et al.}

67. Mutoh T, Kazumata K, Ishikawa T, Terasaka S: Performance of bedside transpulmonary thermodilution monitoring for goal-directed hemodynamic management after subarachnoid hemorrhage. Stroke 40:2368-2374, 2009

68. Naidech AM, Garg RK, Liebling S, Levasseur K, Macken MP, Schuele SU, et al: Anticonvulsant use and outcomes after intracerebral hemorrhage. Stroke 40:3810-3815, 2009

69. Nanda A, Willis BK, Vannemreddy PS: Selective intraoperative angiography in intracranial aneurysm surgery: intraoperative factors associated with aneurysmal remnants and vessel occlusions. Surg Neurol 58:309-315, 2002

70. Neily J, Mills PD, Young-Xu Y, Carney BT, West P, Berger $\mathrm{DH}$, et al: Association between implementation of a medical team training program and surgical mortality. JAMA 304:1693-1700, 2010

71. Neuloh G, Schramm J: Monitoring of motor evoked potentials compared with somatosensory evoked potentials and microvascular Doppler ultrasonography in cerebral aneurysm surgery. J Neurosurg 100:389-399, 2004

72. Ogawa A, Sato H, Sakurai Y, Yoshimoto T: Limitation of temporary vascular occlusion during aneurysm surgery. Study by intraoperative monitoring of cortical blood flow. Surg Neurol 36:453-457, 1991

73. Ogilvy CS, Carter BS, Kaplan S, Rich C, Crowell RM: Temporary vessel occlusion for aneurysm surgery: risk factors for stroke in patients protected by induced hypothermia and hypertension and intravenous mannitol administration. J Neurosurg 84:785-791, 1996

74. Origitano TC, Schwartz K, Anderson D, Azar-Kia B, Reichman OH: Optimal clip application and intraoperative angiography for intracranial aneurysms. Surg Neurol 51:117-128, 1999

75. Pasternak JJ, McGregor DG, Schroeder DR, Lanier WL, Shi Q, Hindman BJ, et al: Hyperglycemia in patients undergoing cerebral aneurysm surgery: its association with long-term gross neurologic and neuropsychological function. Mayo Clin Proc 83:406-417, 2008

76. Paull DE, Mazzia LM, Wood SD, Theis MS, Robinson LD, Carney B, et al: Briefing guide study: preoperative briefing and postoperative debriefing checklists in the Veterans Health Administration medical team training program. Am J Surg 200:620-623, 2010

77. Payner TD, Horner TG, Leipzig TJ, Scott JA, Gilmor RL, DeNardo AJ: Role of intraoperative angiography in the surgical treatment of cerebral aneurysms. J Neurosurg 88:441-448, 1998

78. Qureshi AI, Suri MF, Sung GY, Straw RN, Yahia AM, Saad $M$, et al: Prognostic significance of hypernatremia and hyponatremia among patients with aneurysmal subarachnoid hemorrhage. Neurosurgery 50:749-756, 2002

79. Raabe A, Nakaji P, Beck J, Kim LJ, Hsu FP, Kamerman JD, et al: Prospective evaluation of surgical microscope-integrated intraoperative near-infrared indocyanine green videoangiography during aneurysm surgery. J Neurosurg 103:982-989, 2005

80. Raaymakers TW, Rinkel GJ, Limburg M, Algra A: Mortality and morbidity of surgery for unruptured intracranial aneurysms: a meta-analysis. Stroke 29:1531-1538, 1998

81. Rabinstein AA, Friedman JA, Weigand SD, McClelland RL, Fulgham JR, Manno EM, et al: Predictors of cerebral infarction in aneurysmal subarachnoid hemorrhage. Stroke 35:1862-1866, 2004

82. Rabinstein AA, Weigand S, Atkinson JL, Wijdicks EF: Patterns of cerebral infarction in aneurysmal subarachnoid hemorrhage. Stroke 36:992-997, 2005

83. Rabinstein AA, Wijdicks EF: Cerebral vasospasm in subarachnoid hemorrhage. Curr Treat Options Neurol 7:99107,2005

84. Rahman M, Friedman WA: Hyponatremia in neurosurgical patients: clinical guidelines development. Neurosurgery 65: 925-936, 2009

85. Raslan AM, Fields JD, Bhardwaj A: Prophylaxis for venous thrombo-embolism in neurocritical care: a critical appraisal. Neurocrit Care 12:297-309, 2010

86. Regenbogen SE, Greenberg CC, Resch SC, Kollengode A, Cima RR, Zinner MJ, et al: Prevention of retained surgical sponges: a decision-analytic model predicting relative costeffectiveness. Surgery 145:527-535, 2009

87. Rhoney DH, Tipps LB, Murry KR, Basham MC, Michael DB, Coplin WM: Anticonvulsant prophylaxis and timing of seizures after aneurysmal subarachnoid hemorrhage. Neurology 55:258-265, 2000

88. Ridenour TR, Warner DS, Todd MM, McAllister AC: Mild hypothermia reduces infarct size resulting from temporary but not permanent focal ischemia in rats. Stroke 23:733738,1992

89. Rosengart AJ, Huo JD, Tolentino J, Novakovic RL, Frank JI, Goldenberg FD, et al: Outcome in patients with subarachnoid hemorrhage treated with antiepileptic drugs.J Neurosurg 107: 253-260, 2007

90. Rosenwasser RH, Delgado TE, Buchheit WA, Freed MH: Control of hypertension and prophylaxis against vasospasm in cases of subarachnoid hemorrhage: a preliminary report. Neurosurgery 12:658-661, 1983

91. Rozet I, Vavilala MS: Risks and benefits of patient positioning during neurosurgical care. Anesthesiol Clin 25:631-653, $\mathrm{x}, 2007$

92. Samson D, Batjer HH, Bowman G, Mootz L, Krippner WJ Jr, Meyer YJ, et al: A clinical study of the parameters and effects of temporary arterial occlusion in the management of intracranial aneurysms. Neurosurgery 34:22-29, 1994

93. Sandalcioglu IE, Schoch B, Regel JP, Wanke I, Gasser T, Forsting M, et al: Does intraoperative aneurysm rupture influence outcome? Analysis of 169 patients. Clin Neurol Neurosurg 106:88-92, 2004

94. Schmidt JM, Ko SB, Helbok R, Kurtz P, Stuart RM, Presciutti M, et al: Cerebral perfusion pressure thresholds for brain tissue hypoxia and metabolic crisis after poor-grade subarachnoid hemorrhage. Stroke 42:1351-1356, 2011

95. Schramm J, Cedzich C: Outcome and management of intraoperative aneurysm rupture. Surg Neurol 40:26-30, 1993

96. Schramm J, Møller AR: Intraoperative Neurophysiologic Monitoring in Neurosurgery. Berlin: Springer-Verlag, 1991

97. Shaw MD, Foy PM: Epilepsy after craniotomy and the place of prophylactic anticonvulsant drugs: discussion paper. J R Soc Med 84:221-223, 1991

98. Sherlock M, O’Sullivan E, Agha A, Behan LA, Rawluk $\mathrm{D}$, Brennan P, et al: The incidence and pathophysiology of hyponatraemia after subarachnoid haemorrhage. Clin Endocrinol (Oxf) 64:250-254, 2006

99. Simard JM, Kent TA, Chen M, Tarasov KV, Gerzanich V: Brain oedema in focal ischaemia: molecular pathophysiology and theoretical implications. Lancet Neurol 6:258-268, 2007

100. Sivakumar V, Rajshekhar V, Chandy MJ: Management of neurosurgical patients with hyponatremia and natriuresis. Neurosurgery 34:269-274, 1994

101. Stendel R, Pietilä T, Al Hassan AA, Schilling A, Brock M: Intraoperative microvascular Doppler ultrasonography in cerebral aneurysm surgery. J Neurol Neurosurg Psychiatry 68:29-35, 2000

102. Stulberg JJ, Delaney CP, Neuhauser DV, Aron DC, Fu P, Koroukian SM: Adherence to surgical care improvement project measures and the association with postoperative infections. JAMA 303:2479-2485, 2010

103. Taira T, Tanikawa T: Breakage of Mayfield head rest. J Neurosurg 77:160-161, 1992 


\section{Adverse events in open cerebrovascular neurosurgery}

104. Taylor CL, Selman WR, Kiefer SP, Ratcheson RA: Temporary vessel occlusion during intracranial aneurysm repair. Neurosurgery 39:893-906, 1996

105. Thiele RH, Pouratian N, Zuo Z, Scalzo DC, Dobbs HA, Dumont AS, et al: Strict glucose control does not affect mortality after aneurysmal subarachnoid hemorrhage. Anesthesiology 110:603-610, 2009

106. Todd MM, Hindman BJ, Clarke WR, Torner JC: Mild intraoperative hypothermia during surgery for intracranial aneurysm. N Engl J Med 352:135-145, 2005

107. Umredkar A, Gupta SK, Khandelwal N, Chhabra R, Mathuriya SN, Pathak A, et al: Intracerebral infarcts following clipping of intracranial aneurysms: incidence, clinical correlation and outcome. Br J Neurosurg 24:156-162, 2010

108. van den Berghe G, Wouters P, Weekers F, Verwaest C, Bruyninckx F, Schetz M, et al: Intensive insulin therapy in critically ill patients. N Engl J Med 345:1359-1367, 2001

109. Vermeij FH, Hasan D, Bijvoet HW, Avezaat CJ: Impact of medical treatment on the outcome of patients after aneurysmal subarachnoid hemorrhage. Stroke 29:924-930, 1998

110. Walker IA, Merry AF, Wilson IH, McHugh GA, O'Sullivan E, Thoms GM, et al: Global oximetry: an international anaesthesia quality improvement project. Anaesthesia 64:10511060, 2009

111. Warner DS, Takaoka S, Wu B, Ludwig PS, Pearlstein RD, Brinkhous $\mathrm{AD}$, et al: Electroencephalographic burst suppression is not required to elicit maximal neuroprotection from pentobarbital in a rat model of focal cerebral ischemia. Anesthesiology 84:1475-1484, 1996

112. Warner DS, Zhou JG, Ramani R, Todd MM: Reversible focal ischemia in the rat: effects of halothane, isoflurane, and methohexital anesthesia. J Cereb Blood Flow Metab 11:794-802, 1991

113. Weiser TG, Haynes AB, Dziekan G, Berry WR, Lipsitz SR, Gawande AA: Effect of a 19-item surgical safety checklist during urgent operations in a global patient population. Ann Surg 251:976-980, 2010

114. Weiser TG, Makary MA, Haynes AB, Dziekan G, Berry
WR, Gawande AA: Standardised metrics for global surgical surveillance. Lancet 374:1113-1117, 2009

115. Wiebers DO, Whisnant JP, Huston J III, Meissner I, Brown RD Jr, Piepgras DG, et al: Unruptured intracranial aneurysms: natural history, clinical outcome, and risks of surgical and endovascular treatment. Lancet 362:103-110, 2003

116. Wong JM, Bader AM, Laws ER, Popp AJ, Gawande AA: Patterns in neurosurgical adverse events and proposed strategies for reduction. Neurosurg Focus 33(5):E1, 2012

117. World Health Organization: The Second Global Patient Safety Challenge: Safe Surgery Saves Lives. (http://www. who.int/patientsafety/events/media/SSSL_backgnd_paper. pdf) [Accessed September 24, 2012]

118. Yanamoto H, Nagata I, Nakahara I, Tohnai N, Zhang Z, Kikuchi H: Combination of intraischemic and postischemic hypothermia provides potent and persistent neuroprotection against temporary focal ischemia in rats. Stroke 30:2720 2726,1999

119. Zachenhofer I, Cejna M, Schuster A, Donat M, Roessler K: Image quality and artefact generation post-cerebral aneurysm clipping using a 64-row multislice computer tomography angiography (MSCTA) technology: a retrospective study and review of the literature. Clin Neurol Neurosurg 112:386-391, 2010

Manuscript submitted May 14, 2012.

Accepted July 6, 2012.

Portions of this work were presented in oral abstract form at the New England Neurosurgical Society annual meeting in Chatham Bars, Massachusetts, in June 2011.

Please include this information when citing this paper: DOI: 10.3171/2012.7.FOCUS12181.

Address correspondence to: Atul A. Gawande, M.D., M.P.H., Department of Surgery, Brigham and Women's Hospital, 75 Francis Street, Boston, Massachusetts 02115. email: agawande@partners. org. 